\title{
NATURAL HEDGING OF LIFE AND ANNUITY MORTALITY RISKS
}

\author{
SAMUEL H. COX AND YIJIA LIN
}

\begin{abstract}
The values of life insurance and annuity liabilities move in opposite directions in response to a change in the underlying mortality. Natural hedging utilizes this to stabilize aggregate liability cash flows. We find empirical evidence that suggests that annuity writing insurers who use natural hedging also charge lower premiums than otherwise similar insurers. This indicates that insurers who are able to utilize natural hedging have a competitive advantage. In addition, we show how a mortality swap might be used to provide the benefits of natural hedging.
\end{abstract}

\section{INTRODUCTION}

If future mortality improves relative to current expectations, life insurer liabilities decrease because death benefit payments will be later than expected. However, annuity writers have a loss relative to current expectations because they have to pay annuity benefits longer than expected. If the mortality deteriorates, the situation is reversed: life insurers have losses and annuity writers have gains. Natural hedging utilizes this interaction of life insurance and annuities to a change in mortality to hedge against unexpected changes in future benefit payments.

The purpose of this paper is to study natural hedging of mortality risks and to propose mortality swaps as a risk management tool. Few researchers investigate the issue of natural hedging. Most of the prior research explores the impact of mortality changes on life insurance and annuities separately, or investigates a simple combination of life and pure endowment life contracts (Frees et al., 1996; Marceau and Gaillardetz, 1999; Milevsky and Promislow, 2001; Cairns et al., 2004). Studies on the impact of mortality changes on life insurance focus on "bad" shocks while those on annuities focus on "good" shocks.

Date: July 31, 2005. 
Wang et al. (2003) analyze the impact of the changes of mortality factors and propose an immunization model to hedge risks based on the mortality experience in Taiwan. Life insurance and annuity mortality experience can be very different, so there is "basis risk" involved in using annuities to hedge life insurance mortality risk. Their model cannot pick up this basis risk.

Marceau and Gaillardetz (1999) examine the calculation of the reserves in a stochastic mortality and interest rates environment for a general portfolio of life insurance policies. In their numerical examples, they use portfolios of term life insurance contracts and pure endowment polices, like Milevsky and Promislow (2001). They focus on convergence of simulation results. There is a hedging effect in their results, but they do not pursue the issue.

The paper proceeds as follows: In Section 2, we use an example to illustrate the idea of natural hedging. In Section 3, using market quotes of single-premium immediate annuities (SPIA) from A. M. Best, we find empirical support for natural hedging. That is, insurers who naturally hedge mortality risks have a competitive advantages over otherwise similar insurers. In Section 4, we propose and price a mortality swap between life insurers and annuity insurers. Section 5 is the conclusion and summary.

\section{INTRODUCTORY EXAMPLE}

This example illustrates the idea of a natural hedge. Consider a portfolio of life contingent liabilities consisting of whole life insurance policies written on lives age (35) and immediate life annuities written on lives age (65). If mortality improves, what happens to the insurer's total liability? We know that on average, the insurer will have a loss on the annuity business and a gain on the life insurance business. And if mortality declines, the effects are interchanged. This example shows what can happen if mortality risk increases as a result of a common shock. Here are our assumptions:

(1) Mortality for (35) is based on the 1990-95 Society of Actuaries Male Basic Table and the table for (65) is based on the 1996 US Individual Annuity Mortality Male Basic Table. 
(2) The annuity has an annual benefit of 510 and it is issued as an immediate annuity at age 65.

(3) The face amount of life insurance on (35) is 100,000 and the life insurance is issued at age 35. For this amount of insurance, the present value of liabilities under the life insurance and under the annuity are about equal.

(4) Life insurance premiums and annuity benefits are paid annually. Death benefits are paid at the end of the year of death.

(5) The initial number of life insured $\ell_{35}$ is 10,000 which is the same as that of annuitants $\ell_{65}$.

(6) The mortality shock $\epsilon$ is expressed as a percentage of the force of mortality $\mu_{x+t}$, so it ranges from -1 to 1 , that is, $-1 \leq \epsilon \leq 1$ with probability 1 . Without the shock, the survival probability for a life age $(x)$ at year $t$ is $p_{x+t}=\exp \left(-\mu_{x+t}\right)$. With the shock, the new survival probability $p_{x+t}^{\prime}$ can be expressed as:

$$
p_{x+t}^{\prime}=\left(e^{-\mu_{x+t}}\right)^{1-\epsilon}=\left(p_{x+t}\right)^{1-\epsilon}
$$

If $0<\epsilon \leq 1$, mortality experience improves. If $-1 \leq \epsilon<0$, mortality experience deteriorates.

(7) The term structure of interest rates is flat; there is a single interest rate $i=0.06$.

2.1. Life insurance. For the life insurance, the present value of 1 paid at the end of the year of death is $v^{k+1}$ and the expected present value is

$$
A_{x}=\sum_{k=0}^{\infty} v^{k+1}{ }_{k} p_{x} q_{x+k}
$$

where $x$ is the age when the policy issued ( $x=35$ in this example). For a benefit of $f$ the expected present value is $f A_{x}$.

The present value of 1 per year, paid at the beginning of the year until the year of death, is

$$
\ddot{a} \frac{1-v^{K(x)+1}}{d} .
$$


The expected present value

$$
\ddot{a}_{x}=\mathrm{E}\left[\ddot{a} \frac{}{K(x)+1}\right]=\sum_{k=0}^{\infty} v_{k}^{k} p_{x} .
$$

The net annual premium rate for 1 unit of benefit is determined so that the present value of net premiums is equal to the present value of benefits. This means

$$
P_{x} \ddot{a}_{x}=A_{x}
$$

and for a benefit of $f$ the annual premium is

$$
f P_{x}=f A_{x} / \ddot{a}_{x}
$$

If the insured dies at $K(x)=t$, then the insurer's net loss is the present value of the payment, less the present value premiums. For a unit benefit, the loss is

$$
L=v^{K(x)+1}-P_{x} \ddot{a} \frac{}{K(x)+1}=v^{K(x)+1}-P_{x} \frac{1-v^{K(x)+1}}{d} .
$$

It follows from the definition of the net premium $P_{x}$ that the expected loss is zero. For a benefit of $f$, the loss is $f L$. Of course, the loss can be negative in which case the result turned out in the insurer's favor. On average, the loss is zero.

2.2. Annuities. For an annuitant $(y)$, the present value of 1 per year paid at the beginning of the year is

$$
\ddot{a} \frac{1-v^{K(y)+1}}{d}
$$

The expected present value

$$
\ddot{a}_{y}=\mathrm{E}\left[\ddot{a} \frac{}{K(y)+1}\right]=\sum_{k=0}^{\infty} v_{k}^{k} p_{y} .
$$

The policy is purchased with a single payment of $\ddot{a}_{y}$. In our example $y=65$ and the mortality table is based on annuity experience. For an annual benefit of $b$, the net single premium is $b \ddot{a}_{y}$. The 
company's loss per unit of benefit is

$$
\ddot{a} \frac{\ddot{a}_{y}}{K(y)+1}-1 / d-\ddot{a}_{y}-v^{K(y)+1} / d .
$$

The expected loss is zero.

2.3. Portfolio. The portfolio has a life insurance liability to pay a benefit of $f$ at the end of the year of the death of $(x)$ and a liability to pay a benefit of $b$ at the beginning of each year as long as $(y)$ is alive. The total liability is

$$
f v^{K(x)+1}+b \ddot{a} \overline{K(y)+1} \cdot
$$

To offset the liability the company has

$$
f P_{x} \ddot{a} \frac{{ }_{K(x)+1}}{+b \ddot{a}_{y}} .
$$

The difference is the total loss:

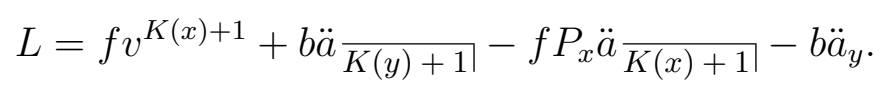

The expected loss is zero. However, this expectation is calculated under the assumption that the mortality follows the tables assumed in setting the premiums. If we replace the before-shock lifetimes with the after shock lifetimes, what happens to the loss?

2.4. Results. Figure 1 shows the percentage deviation of the present value of benefits from the life insurance premiums and that of annuity payments from the total annuity premium collected at time $t=0$. We also show the percentage of deviation from the present value of total premiums collected. Each result includes a shock improvement or deterioration relative to the table mortality, modelled by multiplying the force of mortality by a factor $1-\epsilon$ in each year. With a small mortality improvement shock $\epsilon=0.10$, annuity insurers will lose $2.0 \%$ of their expected total payments. In this scenario, life insurers will gain $5.0 \%$ of their expected total payments. If the above life insurance and annuity are written by the same insurer, the shock has a much smaller effect on 


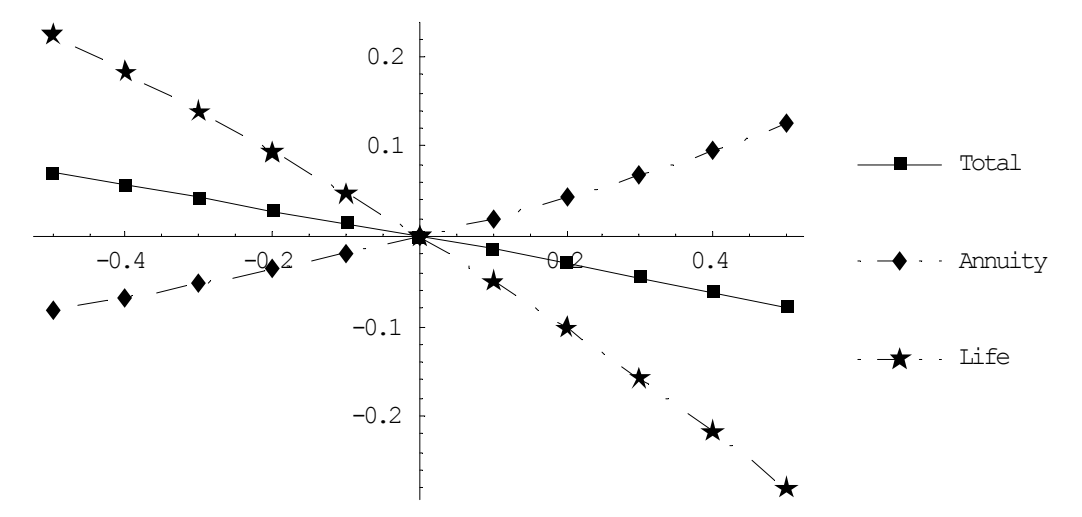

FIGURE 1. The percentage deviation of the present value of benefits from the life insurance premiums, that of annuity payments from the total annuity premium collected and that of total premiums collected at time $t=0$. The $y$-axis represents the percentage loss and the $x$-axis represents different levels of shock improvement or deterioration factor $\epsilon$.

its business (a $1.5 \%$ gain). With a small mortality bad shock $\epsilon=-0.10$, annuity insurers will gain $1.9 \%$ of their expected total payments. In this scenario, life insurers will lose $4.8 \%$ of their expected total payments. If the above life insurance and annuity are sold by the same insurer, a bad shock has little effect on its business (a 1.4\% loss). When there is a big good shock $\epsilon=0.50$, the present value of total annuity payments will increase by $12.5 \%$ and the life insurer will gain $28.0 \%$ of their total expected payments on average. The overall effects will be $7.9 \%$ gain on a big good shock. Writing both life and annuity business reduces the impact of a big bad shock $\epsilon=-0.50$ to a $7.0 \%$ loss. We have illustrated the idea of natural hedging and we see that writing both life and annuities does indeed reduce the insurer's aggregate mortality risk.

\section{Empirical Support For NATURAL HEDging}

Life insurance and annuities have become commodity-like goods, meaning that the price variable is a primary source of competition among insurance industry participants. Through various marketing campaigns, consumers are well aware whether a price offered by an insurer is attractive or not. What does theory say about natural hedging in such a market? 
Financial theory tells us that systematic risk cannot be diversified away because systematic risk influence all businesses. This argument, however, was originally intended for security managers, not corporate managers (Chatterjee and Lubatkin, 1992). Action by corporate managers may alter the underlying systematic risk profiles of their portfolio of business (Chatterjee and Lubatkin, 1990; Helfat and Teece, 1987; Peavy, 1984; Salter and Weinhold, 1979). Thus, while mortality risk may not be hedgeable in financial markets, but it may be reduced or eliminated by some insurers through reinsurance, natural hedging, and, we propose, mortality swaps. Thus financial theory suggests we should find evidence for natural hedging in annuity and life insurance markets.

In addition, the industrial organization literature offers numerous theoretical and empirical models that link integration to a reduction of environmental uncertainty (Arrow, 1975; Carlton, 1979; Mitchell, 1978). Applied to the insurance market, these results suggest that an insurer writing both life insurance and annuities will have reduced risk relative to similar firms writing one of these products. Now let us look at the data.

\subsection{Data, Measures and Methodologies.}

3.1.1. Data and Measures. The annuity prices are actual quotes for SPIAs for a 65-year-old male in each year 1995 to 1998 (Kiczek, 1995, 1996, 1997; A.M.Best, 1998). Each year A.M. Best Company surveyed about 100 companies to obtain quotes for the lifetime-only monthly benefit paid to a $65-$ year-old male with $\$ 100,000$ to invest.

Table 1 describes the annuity payment data and company annual statement data collected by the A.M. Best Company and the National Association of Insurance Commissioners for our two sub-samples. We transformed each quote from a rate of payment per month to an equivalent price,

as follows. If $m$ is the monthly payment rate per $\$ 100,000$ and Price is what the company would charge for an annuity of 1 per year for the annuitant's lifetime, then

$$
\begin{aligned}
100,000 & =12 m \text { Price } \quad \text { and } \\
\text { Price } & =\frac{100,000}{12 m} .
\end{aligned}
$$


TABLE 1. Descriptive insurer statistics for from 1995 to 1998, dollar amounts in millions.

\begin{tabular}{|c|c|c|c|c|}
\hline \multirow[t]{2}{*}{ Variable } & \multirow[t]{2}{*}{ Description } & \multicolumn{3}{|c|}{ Ratio $<0.90(N=299)$} \\
\hline & & Mean & Minimum & Maximum \\
\hline$m$ & Annuity payment rate & 765 & 653 & 992 \\
\hline Price & Equivalent price & 10.93 & 8.40 & 12.76 \\
\hline Resann & Annuity gross reserve & $3,490,298$ & 5,192 & $43,011,379$ \\
\hline Reslife & Life insurance gross reserve & $2,741,170$ & 0 & $45,174,284$ \\
\hline Ratio & $\frac{\text { Reslife }}{\text { Reslife+Resann }}$ & 0.44 & 0.00 & 0.89 \\
\hline Tasset & Total assets & $9,069,208$ & 33,351 & $127,097,380$ \\
\hline Lrate & A. M. Best rating, 1 year prior & 1.59 & 1 & 4 \\
\hline Comexp & $\frac{\text { Commissions }+ \text { expenses }}{\text { Net premiums }}$ & $23.21 \%$ & $2.50 \%$ & $102.20 \%$ \\
\hline \multicolumn{5}{|l|}{ Panel B } \\
\hline \multirow[t]{2}{*}{ Variable } & Description & \multicolumn{3}{|c|}{ Ratio $<0.75(N=243)$} \\
\hline & & Mean & Min & Max \\
\hline$m$ & Annuity payment rate & 765 & 653 & 992 \\
\hline Price & Equivalent price & 10.93 & 8.40 & 12.76 \\
\hline Resann & Annuity gross reserve & $4,082,579$ & 10,535 & $43,011,379$ \\
\hline Reslife & Life insurance gross reserve & $2,412,583$ & 0 & $45,174,284$ \\
\hline Ratio & $\frac{\text { Reslife }}{\text { Reslife+Resann }}$ & 0.35 & 0.00 & 0.75 \\
\hline Tasset & Total assets (in millions) & $9,079,913$ & 33,351 & $127,097,380$ \\
\hline Lrate & A. M. Best rating, 1 year prior & 1.58 & 1 & 4 \\
\hline Comexp & $\frac{\text { Commissions }+ \text { expenses }}{\text { Net premiums }}$ & $21.95 \%$ & $2.50 \%$ & $93.50 \%$ \\
\hline
\end{tabular}

The ratio of life insurance reserves to total annuity and life insurance reserves, denoted Ratio, reflects the level of natural hedging provided by life insurance business to annuity business. The idea is that, of two otherwise similar annuity writers, the one with the higher Ratio value has a better hedge against longevity risk. The better hedge may allow for lower provision for risk in its premiums, and thus lower prices. In addition, this ratio determines the degree to which the insurer writes annuity business. For example, if the ratio is less than 0.90 , the company annuity reserve is more than $10 \%$ of the total.

In an efficient, competitive insurance market, the price of insurance will be inversely related to firm default risk (Phillips et al., 1998; Cummins, 1988; Merton, 1973). That is, a company with 
more default risk, would have lower annuity prices. We use the A. M. Best rating, for the year prior to the quote, as a measure of default risk of annuity insurers. We used the rating to define a numerical variable, Lrate, as follows:

$$
\begin{array}{rr}
\mathrm{A}++, \mathrm{A}+\longrightarrow \text { Lrate }=1 & \mathrm{~A}, \mathrm{~A}-\longrightarrow \text { Lrate }=2 \\
\mathrm{~B}++, \mathrm{B}+\longrightarrow \text { Lrate }=3 & \mathrm{~B}, \mathrm{~B}-\longrightarrow \text { Lrate }=4 \\
\mathrm{C}++, \mathrm{C}+\longrightarrow \text { Lrate }=5 & \mathrm{C}, \mathrm{C}-\longrightarrow \text { Lrate }=6 \\
\mathrm{D} \longrightarrow \text { Lrate }=7 & \mathrm{E}, \mathrm{F}, \text { or } \mathrm{S} \longrightarrow \text { Lrate }=8
\end{array}
$$

This leads to the hypothesis that higher values of Lrate occur with lower annuity prices.

Other factors which may affect the annuity prices are also included in our regression model. We use the logarithm of the company's total gross annuity reserve, $\log ($ Resann), to represent the degree to which the company writes annuity business. The logarithm of the company's total assets, $\log$ (Tasset), controls for the size of the company. The sum of commissions and expenses divided by total written premium, Comexp, measures the company's expenses. Higher expenses should be related to higher annuity prices. The sample includes 322 complete observations from which we extracted two sub-samples of companies that write more than a small amount of annuity business (defined below).

3.1.2. Methodologies. We use the pooled ordinary least square technique to investigate relation between annuity prices and natural hedging, controlling for size, default risk, expenses and year effects. This is the model relationship:

$$
\begin{aligned}
\text { Price }=\alpha & +\beta \text { Ratio }+\gamma_{1} \log (\text { Resann })+\gamma_{2} \log (\text { Tasset })+\gamma_{3} \text { Lrate } \\
& +\gamma_{4} \text { Comexp }+\delta_{1} D_{1998}+\delta_{2} D_{1997}+\delta_{3} D_{1996}+\epsilon
\end{aligned}
$$


where

$$
D_{i}= \begin{cases}1 & \text { if the quote was observed in year } i \\ 0 & \text { if the quote was observed in another year }\end{cases}
$$

and $\epsilon$ is the error term.

Under our hypothesis, the coefficient $\beta$ should be negative indicating that natural hedging allows for lower annuity prices. We run the regression for two sub-samples determined by the proportion of annuity business the company has written, as represented by Ratio ${ }^{1}$. The one sample regression includes sample observations for which Ratio $<0.90$, i.e., at least $10 \%$ of the company's reserve is for its annuity business. This sample rules out companies with very little annuity business. The sample size is $N=299$.

The other sub-sample consists of those observations for which the company has Ratio $<0.75$ so that its life insurance reserves are less than $75 \%$ of its total reserves. The size of this sample is $N=243$. If we eliminate more companies in the range $0.5<$ Ratio $<0.75$, where we might see a stronger effect of natural hedging, then the sample sizes are too small to get adequate significance.

3.2. Findings and Implications. The coefficient estimates are presented in Table 2. Each estimated coefficient is large relative to its standard error. All of the results are significant at the $5 \%$ level or better. White statistics (Greene, 2000) indicate that the distribution of errors is not heteroscedastic; OLS is appropriate. The signs of all the coefficients are consistent with the our hypothesis. Since $\beta$ is negative, annuity writers with more life insurance business tend to have lower annuity prices than similar companies with the same size and rating but less life insurance business. Our story about natural hedging is consisistent with this empirical conclusion. The regression results suggest that annuity writing companies benefit from natural hedging, although these companies may not be making explicit natural hedging decisions.

When annuity business increases relative to life insurance business, the need for longevity risk hedging increases. When we focus on those observations with the proportion of annuity reserve

${ }^{1}$ The proportion of annuity reserves to the sum of annuity reserves and life insurance reserves measures the longevity risk exposure of an annuity insurer; this ratio is the complement of the variable Ratio. $\frac{\text { Resann }}{\operatorname{Reslife}+\operatorname{Resann}}=1-$ Ratio. 
TABLE 2. Pooled OLS regression-Relationship between annuity price and natural hedging

\begin{tabular}{lrr}
\hline Variable & \multicolumn{2}{c}{ Price } \\
\cline { 2 - 3 } & Ratio $<0.75$ & Ratio $<0.90$ \\
\hline Intercept & 10.2900 & 9.6432 \\
Ratio & -0.5487 & -0.4777 \\
$\log ($ Resann $)$ & -0.3171 & -0.1648 \\
$\log ($ Tasset $)$ & 0.3223 & 0.1956 \\
Lrate & -0.1209 & -0.1073 \\
Comexp & 0.9803 & 0.8045 \\
\hline$N$ & 243 & 299 \\
\hline$R^{2}$ & 0.3350 & 0.2913 \\
\hline
\end{tabular}

to the sum of annuity reserve and life insurance reserve higher than $25 \%$, that is Ratio $<0.75$, its coefficient (-0.5487) is larger than the coefficient (-0.4777) obtained for the case Ratio $<0.90$. This suggests that when an annuity writer sells relatively more annuities, the increase in the life insurance hedge has a higher marginal effect in lowering the annuity price.

How do we interpret the coefficient of Ratio $(-0.5487)$ when Ratio $<0.75$ ? Suppose an life insurer has $5 \%$ of its business in life insurance and $95 \%$ of its business in annuities. It sells lifeonly SPIAs to males aged 65 at the market average monthly payouts $\$ 765$. If it can realize full natural hedging, that is, $50 \%$ of business in life insurance and $50 \%$ business in annuities, its SPIA monthly payouts can be increased by $\$ 18$, that is, from $\$ 765$ to $\$ 783$ because it can reduce the risk premium in its price. Its SPIA prices can be more attractive than other similar competitors.

The regression results suggest that when a life insurer writes more annuities, its annuity price goes down because the sign of the annuity business variable, $\log (\operatorname{Resann})$, is negative. The size of an insurer is positively related to the price of its SPIA which may reflect the market power of bigger firms. This is consistent with prior research (Sommer, 1996; Froot and O'Connel, 1997).

Some previous evidence to support the hypothesis that insurance prices reflect firm default risk can be found in (Berger et al., 1992; Sommer, 1996). Our default risk measure Lrate has a negative and significant coefficient, supporting the hypothesis that default risk of annuity insurers is 
reflected in their prices. The sign of the coefficient of the expense variable $\log ($ Comexp $)$ is positive and significant. Higher expenses are consistent with higher prices.

\section{Mortality Swaps}

In section 3, we conclude that natural hedging may allow an annuity writer to lower its prices. However, it may be too expensive and unrealistic for an annuity writer to utilize natural hedging by changing its business composition. If we consider a corporate pension plan as an annuity writer, it may not even be legal for it to issue life insurance. Even for an insurer specialized in annuities, entering the life insurance business may not be practical. Moreover, natural hedging is not a static process. Dynamic natural hedging is required for new business. If an insurer is able to take advantage of natural hedging at a low cost by financial innovation, it can gain competitive advantage in the market by selling annuity products at lower prices. We propose mortality swaps to accomplish this goal.

4.1. Basic Ideas. We are suggesting that a market for mortality swaps may develop in which brokers and dealers offer swaps to annuity writers and separately to life insurers. The broker may match each annuity deal with a life deal or manage its portfolio of mortality swaps on an aggregate basis. As a start toward development of such a market we propose a market-based approach to valuing each side of a mortality swap. The annuity (or survivor risk) side is priced in a way that is consistent with observed prices in the annuity market. Similarly the mortality (or death risk) side is consistent with the life insurance market.

Dowd et al. (2004) propose the possible uses of survivor swaps as instruments for managing, hedging and trading mortality-dependent risks. Their proposed survivor swap involves transferring a mortality risk related to a specific population with another population, that is, one specific longevity risk for another specific longevity risk. Their mortality swap can be used to diversify the longevity risks. However, the survivor swap does not hedge a good shock or a bad shock that strikes across populations (a systematic risk). Our approach is different and it can hedge these shocks. Without any collateral, the swap payments are subject to counter-party risk. That is, one 


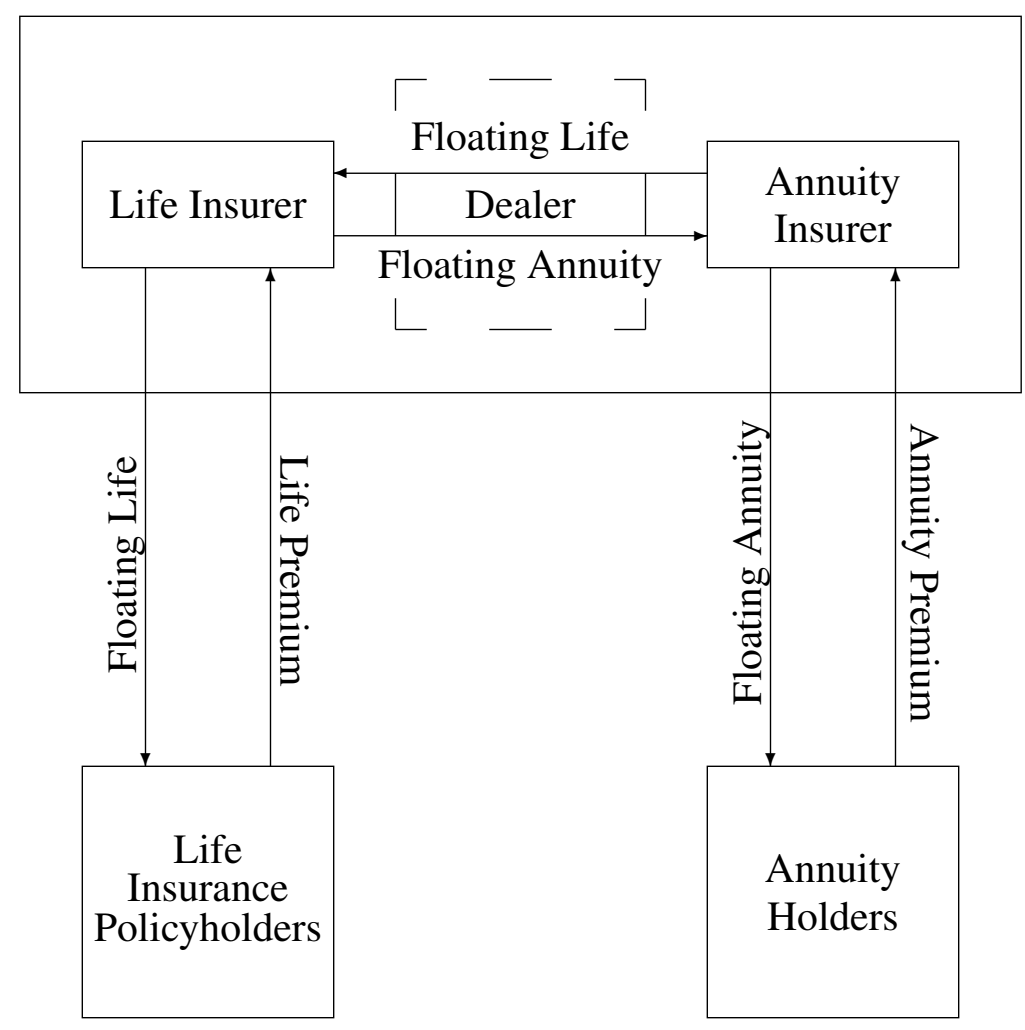

FIGURE 2. Mortality Swap Diagram.

party, the broker or the insurer, may default. We ignore this issue and assume all parties fulfill their contractual obligations. Mortality swaps are described as follows.

Each year the annuity writer pays floating cash flows to the life insurer based on the actual number of deaths in the life insurer's specified portfolio of policies. This provides a benefit to the life insurer if mortality deteriorates, which the annuity writer may pay from its gain due to reduced annuity benefits.

At the same time the life insurer pays an annuity benefit based on the actual number of survivors in the annuity writer's specified portfolio of annuities. If, for example, mortality improves, the life insurer pays the annuity writer but it has a gain on its own life insurance policies. There are no other swap payments. Figure 2 illustrates the mortality swap cash flows. 
4.2. Mortality Swap Design. In order to keep the notation fairly simple, we assume that all of the lives in the life insurance portfolio are subject to the same mortality table, denoted by $(x)$, for pricing purposes. At time 0 we have a portfolio of $\ell_{x}$ lives each insured for an amount $f$. The random number of survivors ${ }^{2}$ to age $x+k$ is denoted $\ell_{x+k}$. The number of deaths in the year $(k, k+1)$ is $d_{x+k}=\ell_{x+k}-\ell_{x+k+1}$. The distribution of $d_{x+k}$ is binomial with parameters $m=\ell_{x}$ and $q={ }_{k} p_{x}-{ }_{k+1} p_{x}$, with $q$ calculated using the mortality table specified at time 0 . The life insurer's aggregate death benefit payment in year $k+1$ amounts to $f d_{x+k}$. At time 0 , the expected value is $\mathrm{E}\left(f d_{x+k}\right)=f m\left({ }_{k} p_{x}-{ }_{k+1} p_{x}\right)$. The insurer's risk is that actual life insurance benefit payments exceed the expected value and so it swaps, agreeing to pay annuity payments (defined below) in exchange for a payment in year $k+1$. The payment from the swap is

$$
f\left(d_{x+k}-\mathrm{E}\left(d_{x+k}\right)\right)_{+}=\left\{\begin{array}{ll}
f\left(d_{x+k}-\mathrm{E}\left(d_{x+k}\right)\right) & \text { if } d_{x+k}>\mathrm{E}\left(d_{x+k}\right) \\
0 & \text { otherwise }
\end{array} \text { for } k=0,1, \ldots\right.
$$

The swap payment limits the net aggregate life insurance benefit from the life insurer to the expected value in each year. Of course, there is a price: The life insurer must provide annuity swap payments when the annuity writer needs them.

The annuity writer pays a benefit $b$ per year to each survivor of an initial cohort of $\ell_{y}$ lives all subject to the same table at time 0 (but usually different from the lives on which the life insurance is written). The distribution of $\ell_{y+k}$ is binomial with parameters $m=\ell_{y}$ and $q={ }_{k} p_{k}$. The total benefit paid at time $k$ is $b \ell_{y+k}$ and the annuity writer needs relief when it exceeds its expected value. This defines the life insurer's swap payment to the annuity writer:

$$
b\left(\ell_{y+k}-\mathrm{E}\left(\ell_{y+k}\right)\right)_{+}=\left\{\begin{array}{ll}
b\left(\ell_{x+k}-\mathrm{E}\left(\ell_{x+k}\right)\right) & \text { if } \ell_{y+k}>\mathrm{E}\left(\ell_{y+k}\right) \\
0 & \text { otherwise }
\end{array} \text { for } k=0,1, \ldots\right.
$$

This is the net cash flow the annuity writer pays in the year $(k, k+1)$ :

\footnotetext{
${ }^{2}$ This is a slight abuse of standard actuarial notation in which $\ell_{x+k}$ denotes the expected number of survivors.
} 
Annuity benefits $\quad b \ell_{y+k}$

To the life insurer $\quad f\left(d_{x+k}-\mathrm{E}\left(d_{x+k}\right)\right)_{+}$

From the life insurer $\quad b\left(\ell_{y+k}-\mathrm{E}\left(\ell_{y+k}\right)\right)_{+}$

Total

$$
\begin{cases}b \ell_{y+k} & \text { if } d_{x+k} \leq \mathrm{E}\left(d_{x+k}\right), \ell_{y+k} \leq \mathrm{E}\left(\ell_{y+k}\right) \\ b \ell_{y+k}+f\left(d_{x+k}-\mathrm{E}\left(d_{x+k}\right)\right) & \text { if } d_{x+k}>\mathrm{E}\left(d_{x+k}\right), \ell_{y+k} \leq \mathrm{E}\left(\ell_{y+k}\right) \\ b \mathrm{E}\left(\ell_{y+k}\right) & \text { if } d_{x+k} \leq \mathrm{E}\left(d_{x+k}\right), \ell_{y+k}>\mathrm{E}\left(\ell_{y+k}\right) \\ b \mathrm{E}\left(\ell_{y+k}\right)+f\left(d_{x+k}-\mathrm{E}\left(d_{x+k}\right)\right) & \text { if } d_{x+k}>\mathrm{E}\left(d_{x+k}\right), \ell_{y+k}>\mathrm{E}\left(\ell_{y+k}\right)\end{cases}
$$

Here is the life insurer's net cash flow in the year $(k, k+1)$ :

Death benefits $\quad f d_{x+k}$

From annuity writer $\quad f\left(d_{x+k}-\mathrm{E}\left(d_{x+k}\right)\right)_{+}$

To annuity writer $\quad b\left(\ell_{y+k}-\mathrm{E}\left(\ell_{y+k}\right)\right)_{+}$

Total

$$
\begin{cases}f d_{x+k} & \text { if } d_{x+k} \leq \mathrm{E}\left(d_{x+k}\right), \ell_{y+k} \leq \mathrm{E}\left(\ell_{y+k}\right) \\ f \mathrm{E}\left(d_{x+k}\right) & \text { if } d_{x+k}>\mathrm{E}\left(d_{x+k}\right), \ell_{y+k} \leq \mathrm{E}\left(\ell_{y+k}\right) \\ f d_{x+k}+b\left(\ell_{y+k}-\mathrm{E}\left(\ell_{y+k}\right)\right) & \text { if } d_{x+k} \leq \mathrm{E}\left(d_{x+k}\right), \ell_{y+k}>\mathrm{E}\left(\ell_{y+k}\right) \\ f \mathrm{E}\left(d_{x+k}\right)+b\left(\ell_{y+k}-\mathrm{E}\left(\ell_{y+k}\right)\right) & \text { if } d_{x+k}>\mathrm{E}\left(d_{x+k}\right), \ell_{y+k}>\mathrm{E}\left(\ell_{y+k}\right)\end{cases}
$$

In each year the swap rearranges the sum of annuity and life insurance benefit payments. The sum is always $b \ell_{y+k}+f d_{x+k}$, but the parties swap adverse outcomes. They need not swap all of their business. The swap contract could be adjusted so that the swap payment triggers are higher than the expected values, for example. Or the contract could specify upper bounds on the annual swap payments.

The underlying portfolios of insured lives and annuitants should be selected so that they are subject to the same general mortality change factors. Change factors can move mortality either way. 
The 1918 flu epidemic is an example which, although the effects varied by age, had a negative impact across populations. Providing pure water and sanitary sewers in European and American cities improved mortality at all ages. The invention of penicillin had a positive effect across populations.

Cairns et al. (2004) discuss a theoretical framework for pricing mortality derivatives and valuing liabilities which incorporate mortality guarantees. Their stochastic mortality models require certain "reasonable" criteria in terms of their potential future dynamics and mortality curve shapes. Mortality changes in a complex manner, influenced by socioeconomic factors, biological variables, government policies, environmental influences, health conditions and health behaviors. Not all of these factors improve with time and, moreover, opinions on future mortality trends vary widely (Buettner, 2002; Hayflick, 2002; Goss et al., 1998; Rogers, 2002). Even if we could settle on a such a dynamic framework, estimation of the parameters may be very difficult. We take a different, static approach.

Wang $(1996,2000,2001)$ has developed a method of pricing risks that unifies financial and insurance pricing theories. This method can be used to price mortality bonds (Lin and Cox, 2005). Now we apply this method to mortality swaps. Consider a random payment $X$ paid at time $T$. If the cumulative density function is $F(x)$, then a "distorted" or transformed istribution $F^{*}(t)$ is determined by parameter $\lambda$ according to the equation

$$
F^{*}(t)=\Phi\left[\Phi^{-1}(F(x))-\lambda\right]
$$

where $\Phi(x)$ is the standard normal cdf. The idea is to determine $\lambda$ so that the time 0 price of $X$ is its discounted expected value using the transformed distribution. Then the formula for the price is

$$
v_{T} \mathrm{E}^{*}(X)=v_{T} \int x d F^{*}(x)
$$

where $v_{T}$ the discount factor determined by the market for risk free bonds at time 0 . Thus, for an insurer's given liability $X$ with cumulative density function $F(x)$, the Wang transform will produce a "risk-adjusted" density function $F^{*}(x)$. The mean value under $F^{*}(x)$, denoted by $\mathrm{E}^{*}[X]$, is the 
risk-adjusted "fair-value" of $X$ at time $T$. Wang's paper describes the utility of this approach. It generalizes well known techniques in finance and actuarial science. Our idea is to use observed annuity prices to estimate the market price of risk for annuities, then use the same distribution to price the annuity side of a mortality swap. For the life insurance side we use the same idea. Term life insurance prices to determine the market price of risk in the life insurance market, giving us the appropriate distribution for pricing the life insurance side of the swap.

The Wang transform is based on the idea that the life insurance or annuity market price takes into account the uncertainty in the mortality table, as well as the uncertainty in the lifetime of a life insured or an annuitant once the table is given. The market price of risk does not, and need not, reflect the risk in interest rates because we are assuming that mortality and interest rate risks are independent. Moreover, we are assuming that investors accept the same transformed distribution and independence assumption for pricing mortality swaps.

4.2.1. Market price of risk. For the annuity distribution function $F_{a}(t)={ }_{t} q_{65}$, we use the 1996 IAM 2000 Basic Table for a male life age sixty-five. Then assuming an expense factor equal to $4 \%$, we use the 1996 market quotes of qualified immediate annuities (Kiczek, 1996) and the US Treasury yield curve on December 30, 1996 to get the market price of risk $\lambda_{a}$ by solving the following equation ${ }^{3}$ numerically for $\lambda$ :

$$
1000(1-0.04)=(7.48 \times 12) \sum_{j=1}^{\infty} v_{j / 12}\left[1-F_{a}^{*}(j / 12)\right]
$$

The sum of over months, measuring time in years, so $v_{j / 12}$ is the discount factor at time 0 for a payment of 1 after $j / 12$ years. And $\left[1-F_{a}^{*}(j / 12)\right]$ is the survival probability usually denoted ${ }_{j / 12} p_{65}$, but using the transformed distribution. This has to be solved numerically for $\lambda_{a}$.

Thus we determined the market price of risk for annuitants is $\lambda_{a}=0.2134$. We think of the 1996 IAM 2000 Basic Table as the actual or physical distribution, which requires a distortion to

${ }^{3}$ The analogous equations in Lin and Cox (2005) are incorrect, although the solutions to the equations as stated here, are correct. 


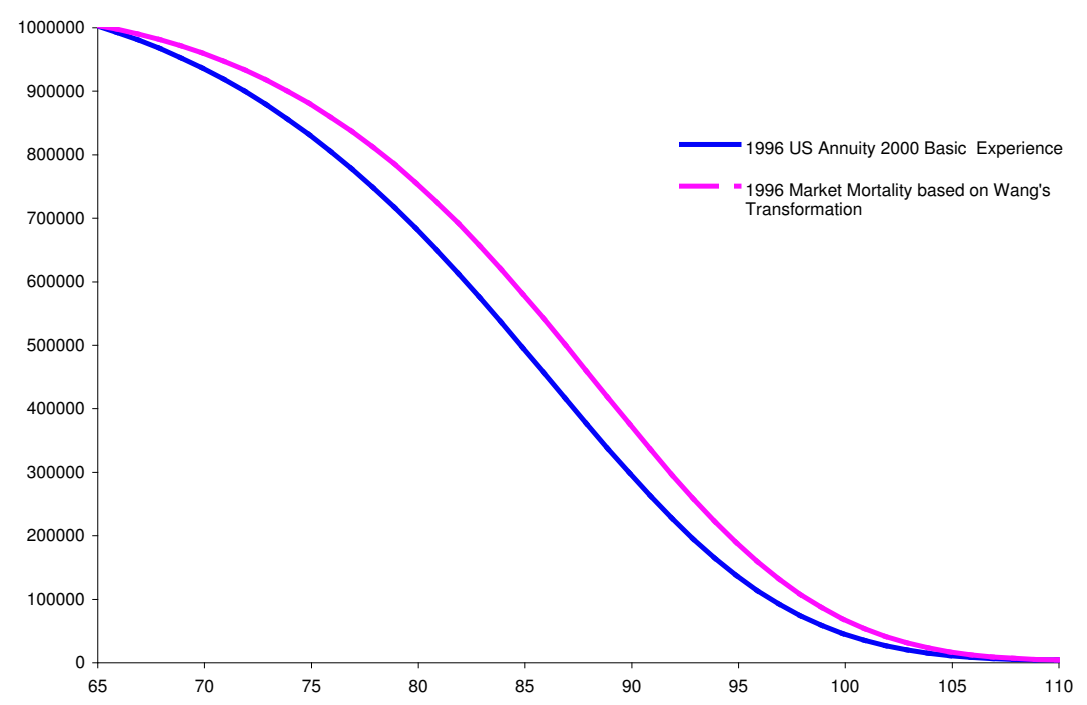

FIGURE 3. The result of applying the Wang transform to the survival distribution based on 1996 IAM experience for males age 65 and prices from Kiczek (1996).

obtain market prices. Figure 3 shows the graphs of $F_{a}(t)$ and $F_{a}^{*}(t)$. The distorted distribution lies to the right and above the physical distribution. This indicates that "the market" view of annuitant mortality is that it will improve relative to the base table.

Similarly, for the life insurance distribution function $F_{l}(t)={ }_{t} q_{35}$, we use the 1990-95 SOA Basic Table for a male life age thirty-five. A.M.Best (1996) reports market quotes for both preferred non-smokers and standard smokers. The 1990-95 SOA Basic Table is created based on a mixture of smokers and non-smokers. We calculated a weighted average of term life insurance prices (\$507.48) using weights based on the incidence of smoking in the US population as reported by the Center for the Disease Control ${ }^{4}$ in 1995. Assuming an expense factor equal to $10 \%$, we use the 1996 average market quotes of ten-year level \$250,000 term life insurance (A.M.Best, 1996) 
based on 97 companies and the US Treasury yield curve on December 30, 1996 to get the market price of risk $\lambda_{l}=0.1933$ by solving the following equation:

$$
507.48 \times(1-0.10)=250,000 \sum_{k=0}^{9} v_{k+1}\left[F^{*}(k+1)-F^{*}(k)\right]
$$

where $v_{k+1}$ is the discount factor for a payment after $k+1$ years. A positive life insurance market price of risk means the market anticipates improved mortality for insured lives, relative to the base table.

4.2.2. Mortality Swap Pricing. We can price each side of the swap now. This will allow us to determine factors $b$ and $f$ for which the two market prices are equal so no cash is paid by either party to initate the contract; they make only contractual swap payments.

The market price of the payment $f\left(d_{x+k}-\mathrm{E}\left(d_{x+k}\right)\right)_{+}$for year $k$ is its discounted expected value $f \mathrm{E}^{*}\left[\left(d_{x+k}-\mathrm{E}\left(d_{x+k}\right)\right)_{+}\right]$. The "*-distribution" of $d_{x+k}$ is binomial with parameters $m=\ell_{x}$ and $q=F^{*}(k+1)-F^{*}(k)$. For large $m$ (over 20 is often suggested), the binomial distribution is approximately normal and we are thinking of portfolios of hundreds of lives. Thus, to a very good approximation,

$$
\mathrm{E}^{*}\left[\left(d_{x+k}-\mathrm{E}\left(d_{x+k}\right)\right)_{+}\right] \approx \sigma_{k} \mathrm{E}\left[\left(X-x_{k}\right)_{+}\right]
$$

where $X$ is a standard normal variable, $\mu_{k}=m q$ and $\sigma_{k}=\sqrt{m q(1-q)}$ are the mean and standard deviation of $d_{x+k}$ and

$$
x_{k}=\frac{\mathrm{E}\left(d_{x+k}\right)-\mu_{k}}{\sigma_{k}} .
$$

For a standard normal variable $X$, there is a formula for this (Lin and Cox, 2005):

$$
\mathrm{E}\left[(X-x)_{+}\right]=\phi(x)-x[1-\Phi(x)]
$$


where $\phi(x)=\Phi^{\prime}(x)=\frac{e^{-x^{2} / 2}}{\sqrt{2 \pi}}$. Thus we can calculate the market price of the life insurance benefit swap payments as

$$
f \sum_{k=0}^{\infty} v_{k+1} \mathrm{E}^{*}\left[\left(d_{x+k}-\mathrm{E}\left(d_{x+k}\right)\right)_{+}\right]=f \sum_{k=0}^{\infty} v_{k+1} \sigma_{k}\left[\phi\left(x_{k}\right)-x_{k}\left[1-\Phi\left(x_{k}\right)\right]\right] .
$$

We apply this same technique to calculate the market value of the annuity benefit swap payments. We only change the definitions of $\mu_{k}$ and $\sigma_{k}$.

$$
b \sum_{k=0}^{\infty} v_{k+1} \mathrm{E}^{*}\left[\left(\ell_{y+k}-\mathrm{E}\left(\ell_{y+k}\right)\right)_{+}\right]=b \sum_{k=0}^{\infty} v_{k+1} \sigma_{k}\left[\phi\left(x_{k}\right)-x_{k}\left[1-\Phi\left(x_{k}\right)\right]\right]
$$

The distribution of $\ell_{y+k}$ is binomial with $m=\ell_{y}$ and $q=1-F^{*}(k)$. The mean are standard deviation are, again, $\mu_{k}=m q$ and $\sigma_{k}=\sqrt{m q(1-q)}$. The remaining parameter is

$$
x_{k}=\frac{\mathrm{E}\left(\ell_{y+k}\right)-\mu_{k}}{\sigma_{k}} .
$$

We calculated these values for a 10-year swap, using $m=10,000$ lives in the annuity and life insurance portfolios. The market value of the life insurance payments, for a death benefit of $\$ 1,000,000$, is $\$ 52,758$. This is about $1.6 \%$ of the net term life insurance premium.

For the annuity payment side of the swap, the market value per 1 dollar of annual benefit, again for 10,000 lives, is $\$ 1,690$. To adjust the average amount of insurance $f$ per term policy to make each side of the swap have the same price, we have

$$
1,690=f \frac{52,758}{100,000}
$$

or $f=3,203$. Thus for each dollar of annual annuity benefit we must have 3,203 dollars of death benefit to make the prices equal at time 0 . Then each party will have the benefit of natural hedging for 10 years. Even though the prices are equal at time 0, the mortality may move one way or the other so that the future market value favors one party. The swap has to be revalued each year to properly reflect each company's position as it may either an asset or liability. 


\section{CONCLUSIONS AND Discussion}

Natural hedging utilizes the interaction of life insurance and annuities to a change in this mortality to stabilize aggregate cash outflows. Our empirical evidences suggest natural hedging is an important factor contributing to annuity price differences after we control for other variables. These differences become more significant for those insurers selling relatively more annuity business. We expect that life insurers may reach the same conclusion.

Most insurance companies still have considerable net exposures to mortality risks even if they reduce their exposure by pooling individual mortality risk and by balancing their annuity positions against their life positions (Dowd et al., 2004). Natural hedging is feasible and mortality swaps make it available widely.

We showed how to design a mortality swap between a life insurer and annuity writer to create a natural hedge. Compared with traditional reinsurance and other derivatives, such as mortality bonds mortality, swaps may be arranged at possibly lower costs and in a more flexible way to suit

diverse circumstances. Thus, there are good reasons to anticipate increased activity in mortality swaps between life insurers and annuity insurers. 


\section{REFERENCES}

A.M.Best (1996). Term insurance survey annual renewable and 10-year level. Best's Review (L/H) 97(5), 61-67.

A.M.Best (1998). Start it up. Best's Review (L/H) 99(4), 77-81.

Arrow, K. (1975). Vertical integration and communication. Bell Journal of Economics 6, 173-183.

Berger, L. A., D. J. Cummins, and S. Tennyson (1992). Reinsurance and the liability crisis. Journal of Risk and Uncertainty 5(3), 253-272.

Buettner, T. (2002). Approaches and experiences in projecting mortality patterns for the oldest old. In Living to 100 and Beyond: Survival at Advanced Ages Symposium. Society of Actuaries.

Cairns, A. J. G., D. Blake, and K. Dowd (2004). Pricing death: Frameworks for the valuation and securitization of mortality risk. Working Paper, Heriot-Watt University, Edinburgh, UK.

Carlton, D. (1979). Vertical integration in competitive markets under uncertainty. Journal of Industrial Economics 27, 189-209.

Chatterjee, S. and M. Lubatkin (1990). Corporate mergers, stockholder diversification and changes in systematic risk. Strategic Management Journal 11(4), 255-268.

Chatterjee, S. and M. Lubatkin (1992). Vertical strategies and market structure: a systematic risk analysis. Organization Science 3(1), 138-156.

Cummins, J. D. (1988). Risk-based premiums or insurance guaranty funds. Journal of Finance 43(4), 823-839.

Dowd, K., D. Blake, A. J. G. Cairns, and P. Dawson (2004). Survivor swaps. Centre for Risk and Insurance Studies Working Paper no.7, University of Nottingham, Nottingham, UK.

Frees, E. W., J. Carriere, and E. Valdez (1996). Annuity valuation with dependent mortality. Journal of Risk and Insurance 63(2), 229-261.

Froot, K. and P. O'Connel (1997). On the pricing of intermediated risks: theory and application to catastrophe reinsurance. Working Paper, Harvard Business School, Boston, MA. 
Goss, S. C., A. Wade, and F. Bell (1998). Historical and projected mortality for Mexico, Canada, and the United States. North American Actuarial Journal 2(4), 108-126.

Greene, W. H. (2000). Econometric Analysis (4th ed.). New Jersey: Prentice-Hall, Inc.

Hayflick, L. (2002). Longevity determination and aging. In Living to 100 and Beyond: Survival at Advanced Ages Symposium. Society of Actuaries.

Helfat, C. and D. Teece (1987). Vertical integration and risk reduction. Journal of Law, Economics, and Organization 3(1), 47-68.

Kiczek, J. A. (1995). Single premium immediate annuity payouts study. Best's Review (L/H) 96(3), $51-54$.

Kiczek, J. A. (1996). Single premium immediate annuity payouts. Best's Review (L/H) 97(4), $57-60$.

Kiczek, J. A. (1997). Comparing the payout. Best's Review (L/H) 97(4), 24-29.

Lin, Y. and S. H. Cox (2005). Securitization of mortality risks in life annuities. Journal of Risk and Insurance 72(2), 227-252.

Marceau, E. and P. Gaillardetz (1999). On life insurance reserve in a stochastic mortality and interest rates environment. Insurance: Mathematics and Economics 25(3), 261-280.

Merton, R. C. (1973). Theory of rational option pricing. Bell Journal of Economics and Management Science 4(1), 141-183.

Milevsky, M. A. and S. D. Promislow (2001). Mortality derivatives and the option to annuitize. Insurance: Mathematics and Economics 29(3), 299-318.

Mitchell, E. (1978). Vertical integration in the oil industry, Chapter Capital cost savings of vertical integration. Washington D. C.: American Enterprise Institute.

Peavy, J. (1984). Modern finance theory, corporate strategy, and public policy: another perspective. Academy of Management Review 9, 152-157.

Phillips, R. D., D. J. Cummins, and F. Allen (1998). Financial pricing of insurance in the multipleline insurance company. Journal of Risk and Insurance 65(4), 597-636.

Rogers, R. (2002). Will mortality improvements continue? National Underwriter 106(34), 11-13. 
Salter, S. and W. Weinhold (1979). Diversification through acqusition. New York: Free Press.

Sommer, D. W. (1996). The impact of firm risk on property-liability insurance prices. Journal of Risk and Insurance 63(3), 501-514.

Wang, J. L., M. L. Yang, and S. Y. C. Pan (2003). Hedging longevity risk in life insurance companies. The Asia-Pacific Risk and Insurance Association 2003 Annual Meeting, Thailand.

Wang, S. (1996). Premium calculation by transforming the layer premium density. ASTIN Bulletin 26(1), 71-92.

Wang, S. (2000). A class of distortion operations for pricing financial and insurance risks. Journal of Risk and Insurance 67(1), 15-36.

Wang, S. (2001). A universal framework for pricing financial and insurance risks. the 6th AFIR Proceedings (September), 679-703.

E-mail address, Samuel H. Cox: samcox@gsu . edu

E-mail address, Yijia Lin: insyllx@langate.gsu.edu

Department of Risk Management \& Insurance, Georgia State University, P.O. Box 4036, AtLANTA, GA 30302-4036 USA 